\title{
Persistent Atrial Fibrillation Hierarchical Activation: from Highest DF Sites to Wave Fractionation at the Boundaries
}

\author{
João Salinet ${ }^{1}$, Fernando S Schlindwein ${ }^{2-3}$, Peter Stafford ${ }^{3}$, Tiago P Almeida ${ }^{1}$, Xin $_{\text {Li }^{2}}$, Frederique J. \\ Vanheusden ${ }^{2}$, María S. Guillem ${ }^{4}, \mathrm{G}$ André $\mathrm{Ng}^{2,3}$ \\ ${ }^{1}$ Engineering, Modelling and Applied Social Sciences Centre, Federal ABC University, Brazil; \\ ${ }^{2}$ Departments of Engineering and Cardiovascular Sciences, University of Leicester, UK; \\ ${ }^{3}$ University Hospitals of Leicester NHS Trust, UK; \\ ${ }^{4}$ Bio-ITACA, Universitat Politècnica de València, Spain.
}

\begin{abstract}
Preclinical studies showed a relationship between high dominant frequency areas (HDFA) and wave fractionation, but evidence in patient who atrial fibrillation $(A F)$ persists for long-term periods (persAF) it is not well defined. This study aims to assess the spatiotemporal organization characteristics at HDFAs is persAF and its impact after per standard pulmonary vein isolation (PVI). Eight persAF patients had a non-contact array catheter deployed into the left atrium to collect up to 2048 AF electrograms (AEG) for 15 s. AEGs were band-pass filtered (3-30 Hz) followed by ventricular farfield cancellation. DF between $4-10 \mathrm{~Hz}$ and its respective organization index (OI) were calculated (4s with $50 \%$ overlap) to produce $3 D \mathrm{DF}$ and OI maps. HDFA defined as the regions within a $0.25 \mathrm{~Hz}$ drop from the highest $D F$ were determined and their centre of gravity (CG) calculated. Highest DF sites showed a higher OI at their core when compared to the periphery $(0.422 \pm 0.101 \mathrm{vs}$. $0.386 \pm 0.126, p=0.02$ ) and increased again organization at sites distant from the HDFAs. Similarly, after PVI, OI remained higher as compared to their periphery $(0.372 \pm 0.026$ vs. $0.332 \pm 0.036, \quad p=0.22)$, but with significant lower values when compared with baseline $(p<0.0001)$. PersAF patients showed higher organization in the HDFAs core when compared with its periphery.
\end{abstract}

\section{Introduction}

Spectral analysis has been applied in invasive and noninvasive atrial fibrillation (AF) recordings to investigative the atrial activity and identify areas within the atria that contain high dominant frequency (DF) signals which may be álrivingô the rhythm [1-3]. These regions showed higher DF components that have been propagated to other locations highlighting a presence in the atria of a DF gradient [4]. DF ablation resulted in interatrial DF gradient reduction, prolonging patientôs sinus rhythm [5]. One of the possible explanations related to this behaviour has been suggested in preclinical studies, showing that micro-source rotors with high-frequency periodic activity were responsible for maintaining AF [6]. These areas with regular, fast and organized activity on the core were found to break and change direction recurrently at a boundary region, resulting in fractionation activity on the atrial electrograms (AEGs) [6]. These findings suggest that one of the possible electrophysiological mechanisms for $\mathrm{AF}$ is related with the hypothesis that the atrium regions with highest $\mathrm{DF}\left(\mathrm{DF}_{\max }\right)$ harbour highly organised activity on their core, and their outer spatial limits show variability on propagation patterns with fractionated activity [6]. Moreover, previous human intracardiac contact studies demonstrated that highest DF boundary areas were circumscribed by rotors, suggesting the occurrence of wave breaks close to these boundary areas [7-8]. Although variability on $\mathrm{DF}_{\max }$ propagation patterns have been previously assessed on noncontact mapping [1], the organization of $\mathrm{DF}_{\max }$ areas core and their boundaries has not been clarified. In this study, we sought to assess the spatio-temporal organization characteristics at HDFAs in the left atrium (LA) of persAF patients and its impact of standard pulmonary vein isolation (PVI) on these organization characteristics.

\section{Methods}

\subsection{Electrophysiological Study}

A non-contact multi-electrode array (MEA) catheter (EnSite 3000, St Jude Medical, USA) was introduced trans-septally into the LA of eight patients (age: $47 \pm 10$ years; AF duration: $34 \pm 25$ months) undergoing catheter ablation of persAF for the first time and with no previous history of heart diseases. Without contact between the 
endocardium wall and electrodes from the MEA, the system generates reconstructed unipolar virtual AEGs projected onto the endocardial 3D geometry of the LA using an inverse solution [1-2]. Anatomical landmarks were identified and annotated on the endocardial 3D LA surface. After AEGs acquisition in AF steady state, the MEA was removed and AF ablation proceeded as per standard practice. Informed consent was obtained from all patients included in the study.

\subsection{Signal processing}

AEGs were sampled at $1200 \mathrm{~Hz}$ and 15-second long segments of non-induced persAF were exported for offline analysis prior and after standard PVI. The AEGs were bandpass filtered between $3 \mathrm{~Hz}$ to $30 \mathrm{~Hz}$ following ventricular far-field influence cancellation [8].

\section{Frequency analysis}

Spectral analysis consisted of identifying the DF $і$ defined as the frequency with the highest power within 4 $\mathrm{Hz}$ to $10 \mathrm{~Hz} \ddot{i}$ to produce sequential $2 \mathrm{D}$ and $3 \mathrm{D} \mathrm{DF}$ density maps of the LA [1-2]. Fast Fourier Transform (FFT) with a Hamming window was applied to the 2048 simultaneous AEGs on sequential segments of $4 \mathrm{~s}$ windows with $50 \%$ overlap (by shifting forward by 2 s) to produce consecutive 3D DF maps. The spectral resolution was $0.25 \mathrm{~Hz}$ and zero padding was applied to produce frequency steps of $0.05 \mathrm{~Hz}$.

An organization index (OI) was calculated by dividing the area under the DF and its harmonics by the total area of the spectrum between $4 \mathrm{~Hz}$ and $20 \mathrm{~Hz}$ [2]. The higher the OI the more prominent the DF is in the AEG. This index allows investigators to identify how 'dominant' the $\mathrm{DF}$ is across the whole AF spectrum.

Once calculated the DF and its respective OI for each simultaneous point, sequential 3D DF and OI maps were obtained. The AEGôs DF for each segment along time is colour coded on the LA 3D surface according to the frequency value. The OI maps were generated by the similar principle with the same colours range (purple for lower DF/OI values and dark-red for higher, Figure 1).

\section{Organization analysis}

For each sequentially obtained DF map, the highest DF areas (HDFA) were defined as the atrial regions within a $0.25 \mathrm{~Hz}$ drop from the highest DF [1-2]. This would produce an area consisting of a collection of points that reflect average regional activity, to minimise the effect of isolated high DF sites. The boundary of this area was highlighted to produce an area representative of a maximum DF áloudôat that particular instant. The centre of gravity (CG) of the HDFA was then identified by averaging the coordinate positions of each point in the cloud, weighted by their respective DF values [1-2].

The mean $\mathrm{OI}$ at the CG of the HDFA $\left(\mathrm{OI}_{\mathrm{CG}}\right)$ was compared with the mean $\mathrm{OI}$ at periphery $\left(\mathrm{OI}_{\mathrm{Per}}\right)$ (Figure 1). To calculate the $\mathrm{OI}_{\mathrm{CG}}, 9$ points were considered (CG point plus its 8 closest neighbours). $\mathrm{OI}_{\text {Per }}$ was computed as the average of the OI at all sites in the DF area boundary.

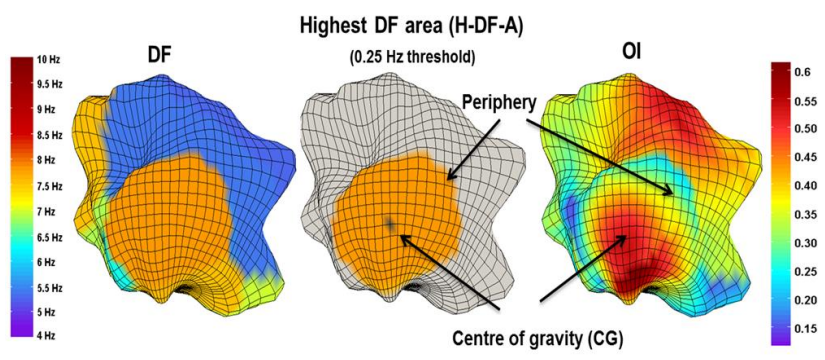

Figure 1: 3D DF and OI maps focusing on the HDFAs identification. (left-hand side) 3D representation including the mapping of the DFs. (middle) The region with the HDFA is identified. (right-hand side) DF organisation from the HDFA showing that the OI at the core has a higher organisation when compared with its periphery.

\subsection{Statistical analysis}

All continuous variables are expressed as mean \pm standard deviation. Shapiro-Wilk normality test was performed. Non-parametric data were log-transformed. A multivariate analysis (MANOVA) was performed to determine differences between the groups and Tukey post hoc tests were conducted. P-values of less than 0.05 were considered statistically significant.

\section{Results}

In total, 156 maps (78 pairs of DF and OI maps) were studied with 96 at baseline and 60 post PVI. HFDAs typically showed a higher OI at their core (i.e., the CG) when compared to the periphery, and increased again organization at sites distant from the highest DF (Figure 2). The MANOVA showed significant interactions between groups $(\mathrm{F}=6.1, \mathrm{p}=0.009)$. In the population, $\mathrm{OI}$ at the core was $0.422 \pm 0.101$ vs. periphery $0.386 \pm 0.126$ $(p=0.02)$. Similarly, OI at their core still tended to be higher as compared to their periphery after PVI $(0.372 \pm 0.026$ vs. $0.332 \pm 0.036, p=0.22)$. After PVI, ablation significantly decreased the OI at the core and at the periphery when compared with baseline $\left(\mathrm{OI}_{\mathrm{CG}}\right.$ : $0.372 \pm 0.026$ vs. $0.422 \pm 0.101, \quad \mathrm{p}<0.0001 ; \quad \mathrm{OI}_{\mathrm{PER}}$ : 


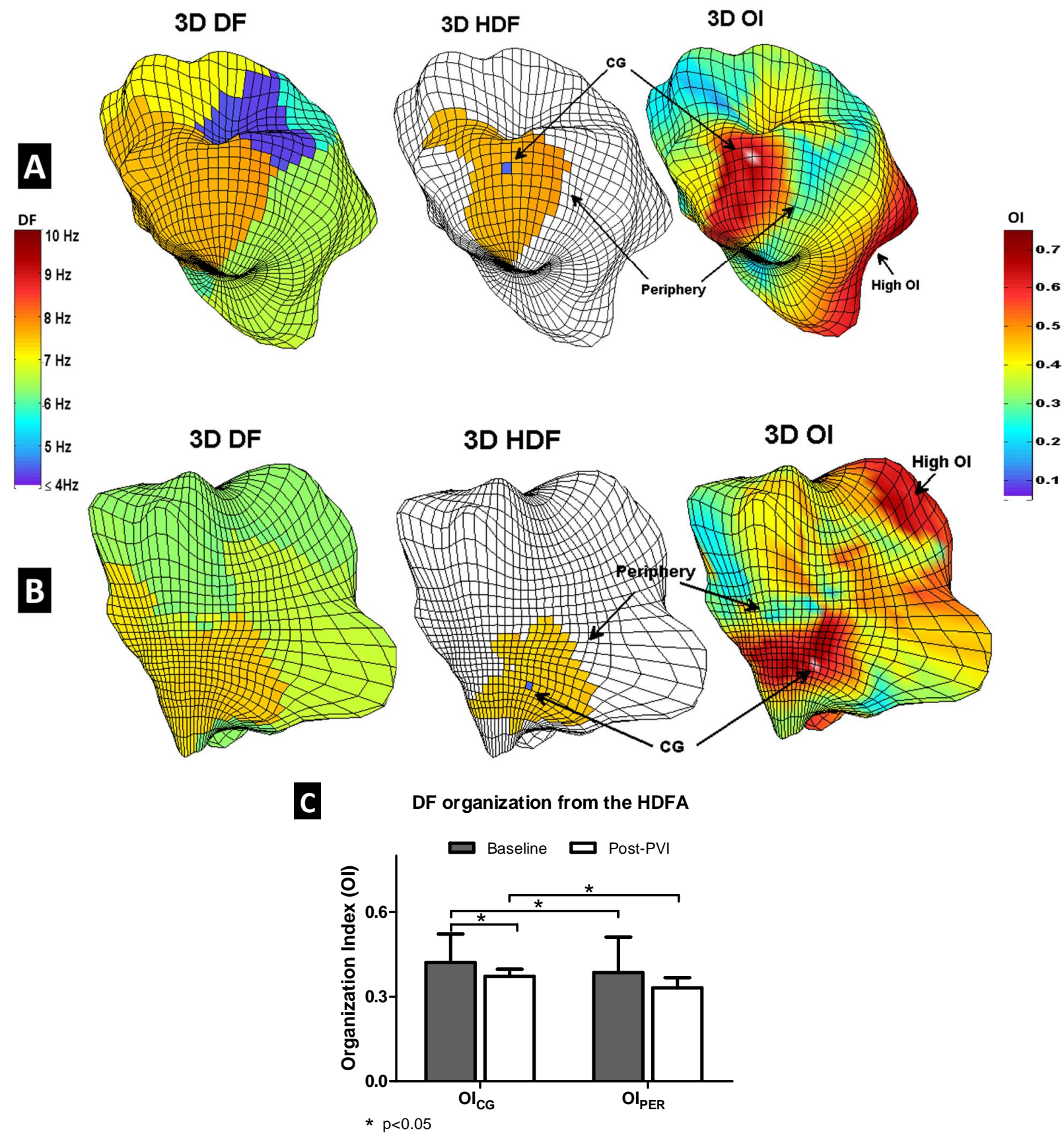

Figure 2: Illustration of 2 sample cases (A and B) of DF and OI mapping focusing on the HDFA identification. Threedimensional representation including the mapping of the DF (left) and its respective HDFA (middle) are presented. DF organization from the HDFA shows that the OI at the core has a higher organization when compared with that of its periphery and increases again in some remaining left atrial areas (right). Figure $2 \mathrm{C}$ presents the relationship between protocols between the degrees of DF organisation at their core $\left(\mathrm{OI}_{\mathrm{CG}}\right) \mathrm{vS}$. at the periphery $\left(\mathrm{OI}_{\mathrm{PER}}\right)$ 


\section{Discussion and conclusions}

Our findings showed that in our population the HDFAs presented highly organized activity on their core and when moving to their boundary areas, the electrograms showed to be fractionated, increasing electrograms organization again in some remaining LA areas. This finding is consistent with a hierarchical activation from the highest DF site and wave fractionation at the boundaries seen previously in preclinical studies [6], and also reported in intracardiac contact AEGs [7-8].

Noncontact frequency mapping of persAF appears to be a reliable technique to investigate potential arrhythmic AF mechanisms which would facilitate location of possible targets for ablation improving persAF outcomes.

\section{Acknowledgements}

This work was supported by Conselho Nacional de Desenvolvimento Científico e Tecnológico (Grants N. 200251/2012-0 and 200598/2009-0) and FAPESP (Grants N. 2017/11103-6 and 2017/00319-8).

\section{References}

[1] Salinet JL, Tuan JH, Sandilands AJ, Stafford PJ, Schlindwein FS, Ng GA. Distinctive patterns of dominant frequency trajectory behaviour in drug-refractory persistent atrial fibrillation: preliminary characterization of spatiotemporal instability. Journal of Cardiovascular Electrophysiology 2014; 25:371-379.

[2] Salinet JL, Schlindwein FS, Stafford PJ, Almeida TP, Xin L, Vanheusden FJ, Guillem MS, Ng GA. Propagation of Meandering Rotors Surrounded by High Dominant Frequency Areas in Persistent Atrial Fibrillation. Heart Rhythm 2017;14:1269-1278.

[3] Guillem MS, Climent AM, Millet J, Arenal A, Fernandez-Aviles F, Jalife J, Atienza F, Berenfeld O. Noninvasive localization of maximal frequency sites of atrial fibrillation by body surface potential mapping. Circ Arrhythm Electrophysiol 2013;6(2):294ї 301.

[4] Jalife J, Berenfeld O, Mansour M. Mother rotors and fibrillatory conduction: a mechanism of atrial fibrillation. Cardiovascular Research 2002;54:204-216.

[5] Atienza F, Almendral J, Jalife J, Zlochiver S,
Ploutz-Snyder R, Torrecilla EG, Arenal A, Kalifa J, Fernandez-Aviles F, Berenfeld O. Realtime DF mapping and ablation of dominant frequency sites in atrial fibrillation with left-toright frequency gradients predicts long-term maintenance of sinus rhythm. Heart Rhythm 2009;6:33-40.

[6] Kalifa J, Tanaka K, Zaitsev AV, Warren M, Vaidyanathan R, Auerbach D, Pandit S, Vikstrom KL, Ploutz-Snyder R, Talkachou A, Atienza F, Guiraudon G, Jalife J, Berenfeld O. Mechanisms of wave fractionation at boundaries of high-frequency excitation in the posterior left atrium of the isolated sheep heart during atrial fibrillation. Circulation 2006;113:626-633.

[7] Samie FH, Berenfeld O, Anumonwo J, Mironov SF, Udassi S, Beaumont J, Taffet S, Pertsov AM, Jalife J. Rectification of the background potassium current: a determinant of rotor dynamics in ventricular fibrillation. Circulation Research 2001;89:1216-1223.

[8] Umapathy K, Nair K, Masse S, Krishnan S, Rogers J, Nash MP, Nanthakumar K. Phase mapping of cardiac fibrillation. Circ Arrhythm Electrophysiol 2010; 3(1):105ï 114.

[9] Salinet JL, Jr., Madeiro JP, Cortez PC, Stafford PJ, Ng GA, Schlindwein FS. Analysis of QRS-T subtraction in unipolar atrial fibrillation electrograms. Medical \& Biological Engineering \& Computing 2013;51:1381-1391.

Address for correspondence

Dr João Salinet

Biomedical Engineering - CECS- UFABC

Email: joao.salinet@ufabc.edu.br 